SILVA, Lucas do Monte. SILVA, Leonardo do Monte. Futebol-empresa: análise da lei de responsabilidade fiscal do futebol brasileiro. Revista Eletrônica Direito e Política, Programa de PósGraduação Stricto Sensu em Ciência Jurídica da UNIVALI, Itajaí, v.11, n.2, 2o quadrimestre de 2016. Disponível em: www.univali.br/direitoepolitica - ISSN 1980-7791.

\title{
FUTEBOL-EMPRESA: ANÁLISE DA LEI DE RESPONSABILIDADE FISCAL DO FUTEBOL BRASILEIRO
}

\section{SOCCER-BUSINESS: ANALYSIS OF SPORT'S FISCAL RESPONSIBILITY}

\section{$\angle A W$}

\section{Lucas do Monte Silva ${ }^{1}$}

Leonardo do Monte Silva ${ }^{2}$

SUMÁRIO: Introdução; 1 . A lei de responsabilidade fiscal do futebol brasileiro e o futebol-empresa; 2 . Profut: a possibilidade de refinanciamento de dívidas fiscais e trabalhistas; 3 Fair play financeiro; 4 Governança desportiva: a desconsideração da pessoa jurídica no caso da gestão temerária; Considerações finais; Referências das fontes citadas.

\section{RESUMO}

O presente trabalho visa a expor as mudanças trazidas pela Lei de Responsabilidade Fiscal do Esporte - LRFE e suas principais consequências no futebol brasileiro. Objetiva-se, por meio da óptica do futebol-empresa, observar se e, caso positivo, como e de que maneira a referida lei poderá produzir efeitos no sentido da modernização do futebol e da profissionalização de sua gestão, não apenas no sentido de promover governança, mas também em sua gestão fiscal. Por meio do método hipotético-dedutivo e da metodologia bibliografia e documental, tem-se como objetivos específicos analisar três pontos principais da LRFE: a) o Programa de Modernização da Gestão e de Responsabilidade Fiscal do Futebol Brasileiro - Profut, verificando as condições necessárias para que as entidades desportivas dele façam parte, bem como dos pressupostos para o refinanciamento de dívidas perante a União; c) a influência que a ideia de fair-play financeiro possui nessa lei; e c) analisar os incentivos à governança desportiva, mais especificamente, por meio da responsabilização solidária e ilimitada dos dirigentes por determinadas situações dispostas em lei, que configuram gestão temerária, como no caso de desvio de finalidade e a criação de risco excessivo e irresponsável para o patrimônio do clube. Observa que a União, no caso vertente, funciona como verdadeira credora, uma vez que permite o parcelamento

\footnotetext{
${ }^{1}$ Acadêmico do curso de Direito na Universidade Federal do Rio Grande do Norte (UFRN). Bolsista do Conselho Nacional de Desenvolvimento Científico e Tecnológico. Membro da equipe editorial da revista Direito e Liberdade (ESMARN). ${ }^{2}$ Acadêmico do curso de Direito no Centro Universitário do Rio Grande do Norte (UNI-RN).
} 
SILVA, Lucas do Monte. SILVA, Leonardo do Monte. Futebol-empresa: análise da lei de responsabilidade fiscal do futebol brasileiro. Revista Eletrônica Direito e Política, Programa de PósGraduação Stricto Sensu em Ciência Jurídica da UNIVALI, Itajaí, v.11, n.2, 2o quadrimestre de 2016. Disponível em: www.univali.br/direitoepolitica - ISSN 1980-7791.

das dívidas, mas, como contraprestação, exige diversas medidas fundamentais para a modernização do esporte no Brasil.

PALAVRAS-ChaVe: Lei de Responsabilidade Fiscal do Esporte. Profut. Modernização do futebol. Governança desportiva.

\section{ABSTRACT}

This work aims to expose the changes brought by Fiscal Responsibility Law of Sports - LRFE and its main consequences in Brazilian football. The objective is, through the perspective of the football-business, see whether, and if so, how and in what way this law can produce effects of the modernization of football and the professionalization of its management, not only to promote governance, but also in its fiscal management. Through the hypothetical-deductive method and methodology literature and documentary, we have specific objectives consider three main points of LRFE: a) the Modernization Program Management and Fiscal Wrestling Responsibility - Profut, verifying the necessary conditions for that sporting bodies his part as well as the assumptions for refinancing debt to the Federal Government; c) the influence that the idea of financial fair play has this law; c) examine incentives to sport governance, more specifically, through the joint and several liability of directors for certain situations laid out in law, which constitute reckless management, as in the case of misuse of purpose and the creation of excessive and irresponsible risk for Heritage Club. Notes that the Union, in this case functions as true creditor, since it allows the installment payment of debts, but in exchange requires a number of key measures for the modernization of the sport in Brazil.

KEYWORDS: Fiscal Responsibility Law of Sports. Profut. Football modernization. Sports governance.

\section{INTRODUÇÃO}

Em 04 de agosto de 2015, após diversos debates entres as entidades desportivas, a União e os atletas (sobretudo, o Bom Senso FC, formado por atletas de diversos clubes), foi promulgada a Lei 13.155, Lei de Responsabilidade Fiscal do Esporte - LRFE, que busca estabelecer princípios e práticas de responsabilidade fiscal e financeira e de gestão transparente e democrática para entidades desportivas profissionais do futebol brasileiro. 
SILVA, Lucas do Monte. SILVA, Leonardo do Monte. Futebol-empresa: análise da lei de responsabilidade fiscal do futebol brasileiro. Revista Eletrônica Direito e Política, Programa de PósGraduação Stricto Sensu em Ciência Jurídica da UNIVALI, Itajaí, v.11, n.2, 2o quadrimestre de 2016. Disponível em: www.univali.br/direitoepolitica - ISSN 1980-7791.

O presente estudo visa a expor as mudanças trazidas por essa lei e suas principais consequências no futebol brasileiro. Objetiva-se, por meio da óptica do futebol-empresa ${ }^{3}$, observar se e, caso positivo, como e de que maneira a referida lei poderá produzir efeitos no sentido da modernização do futebol e da profissionalização de sua gestão, não apenas no sentido de promover governança, mas também em sua gestão fiscal.

Por meio do método hipotético-dedutivo e da metodologia bibliografia e documental, tem-se como objetivos específicos analisar três pontos principais da LRFE: a) o Programa de Modernização da Gestão e de Responsabilidade Fiscal do Futebol Brasileiro - Profut, verificando as condições necessárias para que as entidades desportivas dele façam parte, bem como dos pressupostos para o refinanciamento de dívidas perante a União; c) a influência que a ideia de fair-play financeiro possui nessa lei; e d) analisar os incentivos à governança desportiva, mais especificamente, por meio da responsabilização solidária e ilimitada dos dirigentes por determinadas situações dispostas em lei, que configuram gestão temerária, como no caso de desvio de finalidade e a criação de risco excessivo e irresponsável para o patrimônio do clube.

Por fim, observa-se que a União, sob a óptica dessa lei, funciona como verdadeira credora, uma vez que permite o parcelamento das dívidas, mas, como contraprestação, exige diversas medidas fundamentais para a modernização do esporte no Brasil.

\section{A LEI DE RESPONSABILIDADE FISCAL DO FUTEBOL BRASILEIRO E O FUTEBOL-EMPRESA}

3 Ressalta-se que o termo "futebol-empresa", no presente artigo, é "utilizado para evidenciar o tipo de atividade desenvolvidas pelos clubes de futebol profissional, em contraposição com o ideal associativo que predominava". (PERRUCI, Felipe Falcone. Clube-empresa: o modelo brasileiro para transformação dos clubes de futebol em sociedades empresárias. Dissertação (Mestrado em Direito) - Curso de Mestrado da Faculdade de Direito Milton Campos, Faculdade de Direito Milton Campos, Nova Lima, 2006, p. 200) 
SILVA, Lucas do Monte. SILVA, Leonardo do Monte. Futebol-empresa: análise da lei de responsabilidade fiscal do futebol brasileiro. Revista Eletrônica Direito e Política, Programa de PósGraduação Stricto Sensu em Ciência Jurídica da UNIVALI, Itajaí, v.11, n.2, 2o quadrimestre de 2016. Disponível em: www.univali.br/direitoepolitica - ISSN 1980-7791.

O futebol é um patrimônio cultural brasileiro, podendo ser considerado como referência à própria identidade do país. O fomento e proteção desses patrimônios é um dever do Poder Público, conforme regrado no art. 215 da Constituição Federal de 1988.

O conceito de esporte, estando o futebol incluindo nessa acepção, sofreu alterações nas últimas décadas. Trata-se da evolução de uma mera atividade de lazer e de competição amigável, cultural-social, para englobar também o aspecto econômico, isto é, a ideia de profissionalização do esporte ${ }^{4}$, sem, contudo, perder sua importância social. O futebol, mais especificamente, tendo em vista a sua alta capilaridade na sociedade brasileira se torna um alvo para o aproveitamento político. ${ }^{56}$

Com isso, como já era de se esperar, pessoas físicas e empresas jurídicas começaram a explorar esse esporte. Essa exploração não é intrinsecamente maléfica. Afinal, se o futebol está crescendo e evoluindo

\footnotetext{
${ }^{4}$ ALVES, José Antônio Barros; PIERANTI, Octavio Penna. O estado e a formulação de uma política nacional de esporte no Brasil. $R A E$ electron., São Paulo, v. $6, \mathrm{n}$. 1, June $2007 . \quad$ Disponível em: <http://www.scielo.br/scielo.php?script=sci_arttext\&pid=S1676-

$56482007000100002 \&$ Ing $=$ en\&nrm $=$ iso $>$. p. 2.

${ }^{5}$ ALVES, José Antônio Barros; PIERANTI, Octavio Penna. O estado e a formulação de uma política nacional de esporte no Brasil. RAE electron., São Paulo, v. 6, n. 1, June $2007 . \quad$ Disponível

<http://www.scielo.br/scielo.php?script=sci_arttext\&pid=S1676-

$56482007000100002 \&$ Ing $=$ en\&nrm $=$ iso $>$. p. 6.

${ }^{6}$ ALVES, José Antônio Barros; PIERANTI, Octavio Penna. O estado e a formulação de uma política nacional de esporte no Brasil. RAE electron., São Paulo, v. 6, n. 1 , June $2007 . \quad$ Disponível

<http://www.scielo.br/scielo.php?script=sci_arttext\&pid=S1676-

$56482007000100002 \& \operatorname{lng}=e n \& n r m=i s o>$. p. 6. Nesse sentido, vale lembrar que o "modo de ação do Estado no esporte brasileiro, com a anuência para a participação da iniciativa privada no âmbito gerencial de clubes e federações, criou uma figura política única: o dirigente esportivo e político, que formou uma sólida bancada ligada ao esporte no Poder Legislativo federal. Graças ao prestígio que clubes de massa e os votos de seus torcedores oferecem, dirigentes esportivos, desde a redemocratização do Brasil, ganharam cadeiras de deputados federais, estaduais e de vereadores. Apoiando-se neles, foi possível regular o esporte. Contrariando-os, tentou-se discutir e consertar os problemas por que passava o setor"
} 
SILVA, Lucas do Monte. SILVA, Leonardo do Monte. Futebol-empresa: análise da lei de responsabilidade fiscal do futebol brasileiro. Revista Eletrônica Direito e Política, Programa de PósGraduação Stricto Sensu em Ciência Jurídica da UNIVALI, Itajaí, v.11, n.2, 2o quadrimestre de 2016. Disponível em: www.univali.br/direitoepolitica - ISSN 1980-7791.

em determinado país é esperado (e, até mesmo, necessário) que haja investimentos privados por via de patrocínios, apoios publicitários, empréstimos, dentre outras formas de investimento, direto e indireto, para que esse progresso não se estagne. Por isso, mostra-se necessário separar as duas compressões do termo "explorar" que podem ser utilizadas neste escopo: a) tirar proveito ou utilidade de algo. No caso, as empresas ao explorarem, seguindo este sentido do termo, o futebol, estão aproveitando a capilaridade do futebol para expor suas marcas, seus produtos e se conectar com o consumidor; b) auferir interesses ilícitos, abusando da boa fé, da ignorância ou da posição de algo ou alguém. ${ }^{7}$ No caso de futebol, traz-se a tona a corrupção dos dirigentes, o forte oligarquismo das equipes de futebol e de suas entidades gestoras, bem como dos investidores que exploram jovens jogadores a desempenhar seu ofício no exterior.

A primeira acepção é benéfica, fundamental para que as pessoas jurídicas e os clubes de futebol cresçam juntas, com auxílios mútuos. A segunda, por sua vez, nem tanto. A segunda concepção faz parte do lado obscurto do futebol, cuja fisionomia todos conhecem, mas não conseguem provar.

Os Estados Unidos, por exemplo, são um exemplo modelar da exploração do esporte conforme a primeira acepção acima explorada, a partir da qual observa-se variados efeitos indiretos como apoio e promoção da cultura, educação e esporte. Nesse país, "as competições são determinadas com base em seu potencial econômico e de fomento de negócios, não havendo nesse setor qualquer subsídio direto pelo Estado" ${ }^{8}$. Cabe ressaltar, no entanto, que "a política nacional de esporte [dos Estados Unidos] aposta na interação entre Estado, com um caráter eminentemente regulador,

\footnotetext{
7 Significados do verbete "explorar" no Dicionário Michelis.

${ }^{8}$ ALVES, José Antônio Barros; PIERANTI, Octavio Penna. O estado e a formulação de uma política nacional de esporte no Brasil. $R A E$ electron., São Paulo, v. 6, $\mathrm{n}$. 1 , June 2007. Disponível em: <http://www.scielo.br/scielo.php?script=sci_arttext\&pid=S1676$56482007000100002 \& \operatorname{lng}=e n \& n r m=i s o>$. p. 8.
} 
SILVA, Lucas do Monte. SILVA, Leonardo do Monte. Futebol-empresa: análise da lei de responsabilidade fiscal do futebol brasileiro. Revista Eletrônica Direito e Política, Programa de PósGraduação Stricto Sensu em Ciência Jurídica da UNIVALI, Itajaí, v.11, n.2, 2o quadrimestre de 2016. Disponível em: www.univali.br/direitoepolitica - ISSN 1980-7791.

notadamente no que tange ao nível amador, e iniciativa privada, que comanda clubes e federações."

O esporte no Brasil, por sua vez, ainda está em evolução. Não está sendo nem desprezado, no entanto, também não está promovido e apoiado de forma satisfatória pelos órgãos fomentadores do Estado. Observa-se um certo "receio" dos técnicos, dirigentes de clubes e das entidades gestoras, bem como dos legisladores no campo político, em compreender a necessidade de modificações na forma de ser e no modo de gestão do esporte ${ }^{10}$, assimilando-as e desempenhando de todas as atividades necessárias, dentro de sua competência, para que o futebol continue a crescer, mas agora com de forma transparente e competente.

Esse receio ocorre, conforme aponta $\operatorname{HELAL}\left(1997\right.$, p. 17) ${ }^{11}$ pois:

\begin{abstract}
"Por um lado, a modernização - 'comercialização do espetáculo', 'conscientização' dos jogadores, 'racionalização' do esporte - seria responsável pela destruição de elementos tradicionais do universo do futebol, que falam de 'paixão', 'amor à camisa' e 'futebol-arte'; por outro lado, o tradicionalismo seria responsável pela falta de profissionalismo na administração do futebol, desorganizando as competições e enfraquecendo financeiramente os clubes"
\end{abstract}

Essa aparente antinomia entre as duas dimensões acima pontadas impede o maior progresso do esporte, isto é, a sua racionalização e modernização. Trata-se, conforme destacado, de apenas uma aparente antinomia, uma vez que ambos os lados podem ser harmonizados e

${ }^{9}$ ALVES, José Antônio Barros; PIERANTI, Octavio Penna. O estado e a formulação de uma política nacional de esporte no Brasil. $R A E$ electron., São Paulo, v. $6, \mathrm{n}$. 1 , June 2007.2 Disponível em: <http://www.scielo.br/scielo.php?script=sci_arttext\&pid=S1676-

$56482007000100002 \&$ Ing $=$ en\&nrm $=$ iso > . p. 8.

${ }_{10}$ Adota-se o clássico ditado que diz que "política, futebol, religião e mulher não se discutem e nem se misturam!" a sério.

11 Citado por: SANTOS, L.M.V. A Evolução da Gestão no Futebol Brasileiro. Dissertação de Mestrado. Fundação Getúlio Vargas/ Escola de Administração de Empresas de São Paulo: São Paulo, 2002. 
SILVA, Lucas do Monte. SILVA, Leonardo do Monte. Futebol-empresa: análise da lei de responsabilidade fiscal do futebol brasileiro. Revista Eletrônica Direito e Política, Programa de PósGraduação Stricto Sensu em Ciência Jurídica da UNIVALI, Itajaí, v.11, n.2, 2o quadrimestre de 2016. Disponível em: www.univali.br/direitoepolitica - ISSN 1980-7791.

equilibrados em prol do futebol brasileiro ${ }^{12}$. Ora, a modernização da gestão do futebol não exclui o amor da torcida pelo clube, tampouco suprime o futebol arte dos talentosos jogadores brasileiros. Da mesma forma, a proteção dos elementos tradicionais do futebol não impede que a forma de jogar, no seu sentido técnico, e de gestão seja modificada, para melhor contribuir para o sucesso do futebol no Brasil.

A modernização do futebol e a proteção dos elementos tradicionais desse esporte não são fins em si mesmos. Ao revés, são instrumentos, isto é, meios e formas de incentivar, proteger e tutelar a prática do desporto no Brasil.

A gestão dessas entidades desportivas é fundamental, representando a transição da administração voluntária e amadora de torcedores para uma gestão profissional e sofisticada, que tenha como pauta uma verdadeira governança desportiva. ${ }^{13}$ Nesse sentido, Leoncini e Silva salientam que a "administração dos dirigentes tradicionais de clubes e federações de futebol tem sido apontada como a causa mor que faz com que o futebol brasileiro não consiga aproveitar plenamente seu potencial econômico, principalmente nos chamados agentes diretos - clubes e federações. ${ }^{14}$

Salienta-se que, mesmo adotando a ideia de futebol-empresa, a maiora dos clubes são associações civis sem fins lucrativos, o que não impede

\footnotetext{
12 SOARES, Mario Luiz. A miopia do marketing esportivo dos clubes de futebol no Brasil: proposta de um modelo de gestão de marketing esportivo para os clubes brasileiros. 2007. Tese (Doutorado em Administração) - Faculdade de Economia, Administração e Contabilidade, Universidade de São Paulo, São Paulo, 2007.

13 FERKINS, Lesley; SHILBURY, David; MCDONALD, Gael. The role of the board in building strategic capability: Towards an integrated model of sport governance research. Sport Management Review 8.3 (2005): 195-225, p. 195

14 LEONCINI, Marvio P.; SILVA, Marcia T. Entendendo o futebol como um negócio: um estudo exploratório. Revista Gestão e Produção. Vol. 12, no. 1, p. 11 a 23, 2005, p. 12
} 
SILVA, Lucas do Monte. SILVA, Leonardo do Monte. Futebol-empresa: análise da lei de responsabilidade fiscal do futebol brasileiro. Revista Eletrônica Direito e Política, Programa de PósGraduação Stricto Sensu em Ciência Jurídica da UNIVALI, Itajaí, v.11, n.2, 2o quadrimestre de 2016. Disponível em: www.univali.br/direitoepolitica - ISSN 1980-7791.

ganhos econômicos, contanto que estes sejam revertida para o próprio time em prol do seu crescimento. ${ }^{15}$

É nesse contexto que a discussão sobre a Lei de Responsabilidade Fiscal do Esporte - LRF apresente sua relevância para a gestão do futebol brasileiro. Tal lei, seguindo as experiências realizadas em campeonatos da Europa, possui como objetivo estabelecer princípios e práticas de responsabilidade fiscal e financeira e de gestão transparente e democrática para entidades desportivas profissionais de futebol brasileiro. Dessa forma, busca-se profissionalizar a gestão dessas entidades desportivas.

A União que é a credora de maior parte dessas dívidas, por meio da lei vertente, criou instrumentos que possibilitam o refinanciamento dessas dívidas. Segundo o levantamento feito pela Procuradoria Geral da Fazenda Nacional, o total dos débitos inscritos em Dívida Ativa da União de 103 clubes, até fevereiro de 2015, resulta em $\mathrm{R} \$ 2.330 .672 .633^{16}$. No quadro abaixo, pode-se verificar os clubes com o maior número de dívidas perante à União:

Quadro 1- Dívida de Clubes inscritos em Dívida Ativa da União

\begin{tabular}{|c|c|c|c|}
\hline & $\begin{array}{c}\text { Entidade } \\
\text { desportiva }\end{array}$ & $\begin{array}{l}\text { Divida em } \\
02 / 2014\end{array}$ & $\begin{array}{l}\text { Dívida em } \\
02 / 2015\end{array}$ \\
\hline 1 & $\begin{array}{ll}\text { CLUBE } & \text { ATLETICO } \\
\text { MINEIRO } & \end{array}$ & $R \$ 146,571,523.86$ & $R \$ 284,237,202.34$ \\
\hline 2 & $\begin{array}{l}\text { CLUBE DE REGATAS } \\
\text { DO FLAMENGO }\end{array}$ & $R \$ 269,032,538.33$ & $R \$ 235,039,005.52$ \\
\hline 3 & $\begin{array}{l}\text { BOTAFOGO DE } \\
\text { FUTEBOL E REGATAS }\end{array}$ & $R \$ 192,5$ & $R \$ 215,405,863.23$ \\
\hline 4 & SPORT & $R \$ 169,993,900.10$ & $R \$ 186,546,439.57$ \\
\hline
\end{tabular}

15 SOUZA, Gabriel Menandro Evangelista de. Adoção do regime de empresa e o futebol profissional. 2005. 82 f. Trabalho de Conclusão de Curso. (Graduação em Direito) - Centro Universitário de Brasília, p. 38

16 VEJA. Dívida Ativa da União - Clubes de futebol. Disponível em: < http://veja.abril.com.br/complemento/esporte/pdf/dividas-times-futebol.pdf>. Acesso em: 21 set. 2015. 
SILVA, Lucas do Monte. SILVA, Leonardo do Monte. Futebol-empresa: análise da lei de responsabilidade fiscal do futebol brasileiro. Revista Eletrônica Direito e Política, Programa de PósGraduação Stricto Sensu em Ciência Jurídica da UNIVALI, Itajaí, v.11, n.2, 2o quadrimestre de 2016. Disponível em: www.univali.br/direitoepolitica - ISSN 1980-7791.

\begin{tabular}{|l|l|l|l|}
\hline & $\begin{array}{l}\text { CORINTHIANS } \\
\text { PAULISTA }\end{array}$ & \\
\hline $\mathbf{5}$ & $\begin{array}{l}\text { FLUMINENSE } \\
\text { FOOTBALL CLUB }\end{array}$ & $\mathrm{R} \$ 166,225,164.55$ & $\mathrm{R} \$ 173,901,960.00$ \\
\hline $\mathbf{6}$ & $\begin{array}{l}\text { CLUB DE REGATAS } \\
\text { VASCO DA GAMA }\end{array}$ & $\mathrm{R} \$ 146,885,265.80$ & $\mathrm{R} \$ 148,788,733.96$ \\
\hline $\mathbf{7}$ & $\begin{array}{l}\text { SPORT CLUB } \\
\text { INTERNACIONAL }\end{array}$ & $\mathrm{R} \$ 127,210,059.29$ & $\mathrm{R} \$ 129,657,825.20$ \\
\hline $\mathbf{8}$ & $\begin{array}{l}\text { GUARANI FUTEBOL } \\
\text { CLUBE }\end{array}$ & $\mathrm{R} \$ 90,670,540.98$ & $\mathrm{R} \$ 101,961,936.45$ \\
\hline $\mathbf{9}$ & $\begin{array}{l}\text { SOCIEDADE } \\
\text { ESPORTIVA } \\
\text { PALMEIRAS }\end{array}$ & $\mathrm{R} \$ 44,904,072.50$ & $\mathrm{R} \$ 73,850,363.27$ \\
\hline $\mathbf{1 0}$ & $\begin{array}{l}\text { ASSOCIACAO } \\
\text { PORTUGUESA } \\
\text { DESPORTOS }\end{array}$ & $\mathrm{RE} \$ 36,674,541.99$ & $\mathrm{R} \$ 68,630,324.5$ \\
\hline
\end{tabular}

Fonte: Procuradoria Geral da Fazenda Nacional (2015). Adaptado pelo autor.

A possibilidade do refinanciamento, no entanto, só se torna viável no caso da entidade desportiva pleiteante cumprir determinadas exigências legais, nos termos do art. $4^{\circ}$ da Lei 13.155 , como, por exemplo, a regularidade das obrigações fiscais e trabalhistas, fixação do período de mandato para o presidente do clube e comprovação de existência e autonomia do seu conselho fiscal.

Com efeito, em termos práticos, o Estado atua como verdadeiro credor de uma recuperação judicial. No caso, é possível o refinanciamento das dívidas, mas isso só ocorre caso os clubes cumpram exigências fundamentais para a modernização do futebol e sua gestão, pautando-se por uma governança desportiva. Em outras palavras: o refinanciamento não é uma mera benesse estatal, uma vez que a adoção desta só é possível com o cumprimento de diversas contraprestações, as quais, por sua vez, são fundamentais para o futuro do esporte.

\section{PROFUT: A POSSIBILIDADE DE REFINANCIAMENTO DE DÍVIDAS FISCAIS E TRABALHISTAS}


SILVA, Lucas do Monte. SILVA, Leonardo do Monte. Futebol-empresa: análise da lei de responsabilidade fiscal do futebol brasileiro. Revista Eletrônica Direito e Política, Programa de PósGraduação Stricto Sensu em Ciência Jurídica da UNIVALI, Itajaí, v.11, n.2, 2o quadrimestre de 2016. Disponível em: www.univali.br/direitoepolitica - ISSN 1980-7791.

Um dos instrumentos elaborados pela LRFE é o Programa de Modernização da Gestão e de Responsabilidade Fiscal do Futebol Brasileiro - Profut, que tem com objetivo de promover a gestão transparente e democrática e o equilíbrio financeiro das entidades desportivas profissionais de futebol.

Segundo a Lei 13.155/2015, entende-se como entidade desportiva profissional de futebol a entidade de prática desportiva envolvida em competições de atletas profissionais, nos termos dos arts. 26 e 28 da Lei no 9.615/1998 (que versa sobre normas gerais do desporto), as ligas em que se organizarem e as respectivas entidades de administração de desporto profissional.

A adesão ao Profut ocorre com o requerimento das entidades desportivas profissionais de futebol do parcelamento sobre o qual a lei dispõe (art. $3^{\circ}$ ). Dessa afirmação, cabe ressaltar dois pontos. Primeiro, a adesão não é obrigatória para todos as entidades desportivas, sendo exigido um requerimento destas para que as condições legais sejam aplicáveis em seus respectivos casos. Segundo, a adesão ao Profut é condição para o parcelamento especial dos débitos dessas entidades perante a União, ou seja, não é possível que esse evento ocorra, sem que os entes adotem as obrigações legais do Profut. A partir do momento que a entidade não cumpre as exigências do referido programa, a possibilidade do parcelamento encontra seu fim.

As condições para que as entidades desportivas profissionais de futebol mantenham-se no Profut se dividem em dez.

A primeira condição é a regularidade das obrigações trabalhistas e tributárias federais correntes, vencidas a partir da data de publicação da LRFE, inclusive as retenções legais, na condição de responsável tributário, na forma da lei. Trata-se de priorizar os direitos básicos dos atletas e dos funcionários do clube em vez de novas contratações e investimentos, que propõe "novos caminhos" para o clube, mas sem pagar seus próprios 
SILVA, Lucas do Monte. SILVA, Leonardo do Monte. Futebol-empresa: análise da lei de responsabilidade fiscal do futebol brasileiro. Revista Eletrônica Direito e Política, Programa de PósGraduação Stricto Sensu em Ciência Jurídica da UNIVALI, Itajaí, v.11, n.2, 2o quadrimestre de 2016. Disponível em: www.univali.br/direitoepolitica - ISSN 1980-7791.

funcionários em dia.

A segunda é a necessidade de fixação do período do mandato de seu presidente ou dirigente máximo e demais cargos eletivos em até quatro anos, permitida uma única recondução. Com essa exigência a LRFE tem como objetivo obstar que o cargo de presidente ou dirigente seja exercido por longos períodos de tempo, como ocorre na CBF e na FIFA, tendo em vista que o futebol e, sobretudo as entidades gestores estaduais, no âmbito brasileiro e os países de menor visibilidade, no âmbito internacional, possuem como base a tradição, isto é, preferem continuar da maneira que já é utilizado pelos dirigentes, uma vez que eventual mudança poderá prejudicá-los.

Já a terceira é a comprovação da existência e autonomia do seu conselho fiscal. O conselho fiscal deve ser entendido como autônomo quando possui asseguradas condições de instalação, de funcionamento e de independência, garantidas, no mínimo, por meio das seguintes medidas $\left(3^{\circ}\right)$ : I - escolha de seus membros mediante voto ou outro sistema estabelecido previamente à escolha; II - exercício de mandato de seus membros, do qual somente possam ser destituídos nas condições estabelecidas previamente ao seu início e determinadas por órgão distinto daquele sob a sua fiscalização; e III - existência de regimento interno que regule o seu funcionamento.

Relevante ressaltar, primeiramente, a importância da efetiva autonomia do conselho fiscal. Hodienrnamente, não é incomum que as entidades desportivas já possuam um conselho fiscal. Ocorre que estas não possuem autonomia, servindo, por vezes, como mera figura simbólica, tendo em vista que nesses casos os dirigentes decidem como quiserem e da forma que querem, gastando grandes quantias, sem se preocupar com 
SILVA, Lucas do Monte. SILVA, Leonardo do Monte. Futebol-empresa: análise da lei de responsabilidade fiscal do futebol brasileiro. Revista Eletrônica Direito e Política, Programa de PósGraduação Stricto Sensu em Ciência Jurídica da UNIVALI, Itajaí, v.11, n.2, 2o quadrimestre de 2016. Disponível em: www.univali.br/direitoepolitica - ISSN 1980-7791.

as contas que serão prestadas ao conselho fiscal ${ }^{17}$. Ademais, salienta-se que as medidas apresentadas se referem ao mínimo exigido, sendo, por evidente, recomendado que os clubes não se limitem a estas, indo além, fortalecendo esse importante órgão.

A quarta e quinta, por sua vez, se referem a proibição de antecipação ou comprometimento de receitas referentes a períodos posteriores ao término da gestão ou do mandato, salvo: a) o percentual de até $30 \%$ (trinta por cento) das receitas referentes ao $1^{\circ}$ (primeiro) ano do mandato subsequente; e b) em substituição a passivos onerosos, desde que implique redução do nível de endividamento, bem como dispõe que devese buscar a redução do défice, a partir de $1^{0}$ de janeiro de 2017, para até $10 \%$ (dez por cento) de sua receita bruta apurada no ano anterior; e a partir de 10 de janeiro de 2019, para até $5 \%$ (cinco por cento) de sua receita bruta apurada no ano anterior.

Nota-se que a lei em comento busca inspiração na Lei de Responsabilidade Fiscal - LRF ao impor limites de compromentimento de receitas de futuros mandatos que acabam por prejudicar o nível de investimentos de futuras gestões. Frise-se que a LRFE não proibiu o comprometimento de receitas referentes a períodos posteriores ao término da gestão ou do mandato, tendo em vista que, por vezes, para o crescimento da entidade desportiva o investimento de longo prazo é necessário, mas sim impôs um percentual razoável de até 30\% (trinta por cento) das receitas referentes ao $1^{\circ}$ (primeiro) ano do mandato subsequente. No mesmo contexto, a lei em comento apresenta prazos para adequação da entidade quanto ao défice em relação as receitas brutas apuradas, salientando, no entanto, que as entidades desportivas profissionais com faturamento anual inferior a uma vez e meia o teto do

17 GLOBOESPORTE.COM. Conselho Fiscal reprova contas do Vasco pelo quarto ano consecutive. 
SILVA, Lucas do Monte. SILVA, Leonardo do Monte. Futebol-empresa: análise da lei de responsabilidade fiscal do futebol brasileiro. Revista Eletrônica Direito e Política, Programa de PósGraduação Stricto Sensu em Ciência Jurídica da UNIVALI, Itajaí, v.11, n.2, 2o quadrimestre de 2016. Disponível em: www.univali.br/direitoepolitica - ISSN 1980-7791.

faturamento da empresa de pequeno porte não precisam reduzir o défice da maneira que a lei exige.

Já a sexta condição é a publicação das demonstrações contábeis padronizadas, separadamente, por atividade econômica e por modalidade esportiva, de modo distinto das atividades recreativas e sociais, após terem sido submetidas a auditoria independente.

Essa condição diz respeito a três questões merecedoras de registro. Primeiro, exige que as demonstrações contábeis sejam publicadas para que os interessados possam fiscalizá-las. Segundo, dispõe que deve existir uma separação por atividade econômica e por modalidade esportiva, de modo distinto das atividades recreativas e sociais, de modo a assegurar que as grandes entidades desportivas não se aproveitem do seu tamanho e as diversas áreas de investimento, para obscurecer o dispêndios dos seus recursos. Terceiro, é relevante ressaltar que informa a necessidade de submissão a uma auditoria independente, o que legitima uma fiscalização justa por terceiros, que não possuem relação direta com o clube-empresa, como ocorre no caso de conselho fiscal. Nesse último caso, em situações de entidades desportivas profissionais com faturamento anual inferior a uma vez e meia o teto do faturamento da empresa de pequeno porte, tendo em vista as próprias particularidades desses times, a LRFE autoriza que seja realizada a contratação de contador para o exercício da função de auditor independente.

No que tange à sétima condição, trata-se da necessidade do cumprimento dos contratos e regular pagamento dos encargos relativos a todos os profissionais contratados, referentes a verbas atinentes a salários, de Fundo de Garantia do Tempo de Serviço - FGTS, de contribuições previdenciárias, de pagamento das obrigações contratuais e outras havidas com os atletas e demais funcionários, inclusive direito de imagem, ainda que não guardem relação direta com o salário. 
SILVA, Lucas do Monte. SILVA, Leonardo do Monte. Futebol-empresa: análise da lei de responsabilidade fiscal do futebol brasileiro. Revista Eletrônica Direito e Política, Programa de PósGraduação Stricto Sensu em Ciência Jurídica da UNIVALI, Itajaí, v.11, n.2, 2o quadrimestre de 2016. Disponível em: www.univali.br/direitoepolitica - ISSN 1980-7791.

A LRFE, com a imposição dessa condição, demonstra que uma de suas prioridades é que os atletas e funcionários tenham seus direitos trabalhistas, previdenciários e constitucionais garantidos, impondo o pagamento dos seus salários, FGTS, contribuições previdenciárias e obrigações contratuais, como o direito de imagem, que apesar de serem direitos básicos do trabalhador, por vezes, acabam sendo olvidados pelos clubes em prol de novas contratações.

A oitava condição se refere à previsão, no estatuto ou contrato social da entidade desportiva sobre o afastamento imediato e inelegibilidade, pelo período de, no mínimo, cinco anos, de dirigente ou administrador que praticar ato de gestão irregular ou temerária.

Trata-se da necessidade que os clubes internalizem as consequências da LRFE em seus estatutos e contratos sociais, informando sobre os procedimentos de afastamento imediato e inelegibilidade de dirigente ou administrador que praticar ato de gestão irregular ou temerária, pelo período de, no mínimo, o cinco anos, assim, possibilitando que cada entidade desportiva, dentro dos parâmetros constitucionais, sobretudo da proporcionabilidade, imponha período maior do que gizado na lei.

A nona condição é a demonstração de que os custos com folha de pagamento e direitos de imagem de atletas profissionais de futebol não superam $80 \%$ (oitenta por cento) da receita bruta anual das atividades do futebol profissional.

A LRF pode ser vista, novamente, como fonte de inspiração para essa condição ao impor limites da receira bruta anual para gastos com folha de pagamento e direitos de imagem. No caso da LRF, tendo em vista os sujeitos para qual se dirige, impõe limites com dispêndio total com pessoal, com base na receita corrente líquida, sendo da União, 50\%, e dos Municipios e Estados, 50\%. Com essa medida, a lei tem como objetivo garantir a sustentabilidade das entidades desportivas, uma vez que como 
SILVA, Lucas do Monte. SILVA, Leonardo do Monte. Futebol-empresa: análise da lei de responsabilidade fiscal do futebol brasileiro. Revista Eletrônica Direito e Política, Programa de PósGraduação Stricto Sensu em Ciência Jurídica da UNIVALI, Itajaí, v.11, n.2, 2o quadrimestre de 2016. Disponível em: www.univali.br/direitoepolitica - ISSN 1980-7791.

qualquer empresa (no caso, clube-empresa), há necessidade de margem para investimentos no clube e no seu crescimento, e não apenas nos gastos com folha de pagamento dos jogadores. Tal condição, no entanto, não é exigida no caso das entidades desportivas profissionais com faturamento anual inferior a uma vez e meia o teto do faturamento da empresa de pequeno porte que trata o inciso II do art. $3^{\circ}$ da Lei Complementar no 123.

Por fim, a última condição é a manutenção de investimento mínimo na formação de atletas e no futebol feminino e oferta de ingressos a preços populares, mediante a utilização dos recursos provenientes da remuneração pela cessão de direitos de que trata o inciso I do $\S 2^{\circ}$ do art. 28 da lei em espécie, que dispõe sobre a instituição da Loteria Instantânea Exclusiva - LOTEX.

Importamte salientar também como preocupação dessa lei a democracatização dos órgãos e conselhos competentes, determinando ser necessário (e, não, apenas facultativo) a participação dos atletas nas decisões desses entes, ou seja, garante a representação da categoria de atletas no âmbito dos órgãos e conselhos técnicos incumbidos da aprovação de regulamentos das competições. Além de acentuar a necessidade que as entidades publiquem, em sítio eletrônico próprio, documentos que atestem o cumprimento das condições expostas alhures, sendo garantido, no entanto, o sigilo acerca dos valores pagos a atletas e demais profissionais contratados.

No que se refere ao parcelamento especial de débitos das entidades desportivas profissionais de futebol perante a União, realizadas pelas entidades que aderirem ao Profut poderão parcelar os débitos na Secretaria da Receita Federal do Brasil do Ministério da Fazenda, na Procuradoria-Geral da Fazenda Nacional e no Banco Central do Brasil, e os débitos previstos na Subseção II, no Ministério do Trabalho e Emprego. 
SILVA, Lucas do Monte. SILVA, Leonardo do Monte. Futebol-empresa: análise da lei de responsabilidade fiscal do futebol brasileiro. Revista Eletrônica Direito e Política, Programa de PósGraduação Stricto Sensu em Ciência Jurídica da UNIVALI, Itajaí, v.11, n.2, 2o quadrimestre de 2016. Disponível em: www.univali.br/direitoepolitica - ISSN 1980-7791.

Entre estes, aplica-se aos débitos tributários ou não tributários, cujos fatos geradores tenham ocorrido até a data de publicação da Lei, constituídos ou não, inscritos ou não como dívida ativa, mesmo que em fase de execução fiscal ajuizada, ou que tenham sido objeto de parcelamento anterior, não integralmente quitado, ainda que cancelado por falta de pagamento.

Sobreleva notar, no entanto, que o requerimento de parcelamento implica confissão irrevogável e irretratável dos débitos abrangidos pelo parcelamento e configura confissão extrajudicial, podendo a entidade de prática desportiva profissional, a seu critério, não incluir no parcelamento débitos que se encontrem em discussão na esfera administrativa ou judicial, estejam ou não submetidos à causa legal de suspensão de exigibilidade.

Ademais, para inclusão no parcelamento de que trata os débitos em estudo que se encontrem vinculados a discussão administrativa ou judicial, submetidos ou não a hipótese legal de suspensão, o devedor deverá desistir de forma irrevogável, até o prazo final para adesão, de impugnações ou recursos administrativos, de ações judiciais propostas ou de qualquer defesa em sede de execução fiscal e, cumulativamente, renunciar a quaisquer alegações de direito sobre as quais se fundam os processos administrativos e as ações judiciais.

No que tange ao modo de realização, a dívida objeto do parcelamento será consolidada, no âmbito de cada órgão responsável pela cobrança, na data do pedido, e deverá ser paga em até duzentas e quarenta parcelas, com redução de $70 \%$ (setenta por cento) das multas, $40 \%$ (quarenta por cento) dos juros e $100 \%$ (cem por cento) dos encargos legais, sendo o valor das parcelas não inferior a $\mathrm{R} \$ 3.000,00$ (três mil reais). Desse modo, a União oferece incentivos para que as entidades desportivas optem por adentrar no PROFUT, oferecendo prazos de até 20 anos para 
SILVA, Lucas do Monte. SILVA, Leonardo do Monte. Futebol-empresa: análise da lei de responsabilidade fiscal do futebol brasileiro. Revista Eletrônica Direito e Política, Programa de PósGraduação Stricto Sensu em Ciência Jurídica da UNIVALI, Itajaí, v.11, n.2, 2o quadrimestre de 2016. Disponível em: www.univali.br/direitoepolitica - ISSN 1980-7791.

que sejam realizados os pagamentos das dívidas e com reduz de multas, juros e encargos legais, os quais, em regra, em termos gerais, acabavam aumentando os valores dos débitos exigidos.

\section{FAIR PLAY FINANCEIRO}

O fair play financeiro (Financial Fair Play Regulations - FFP) foi aprovado pelo Comitê Executivo da UEFA (Union of European Football Associations , em português, União das Federações Europeias de Futebol) no ano de 2009 e tem como objetivo precípuo um balanceamento financeiro positivo, ou seja, visa impedir que os clubes profissionais de futebol gastem mais do que a arrecadem, sob pena de sofrerem sanções, como desqualificações de competições e multas.

As intenções centrais desse sistema montam-se em pagamento salarial em dia, incentivo a investimentos a longo prazo no setor juvenil e em infraestrutura, possibilidade dos clubes competirem com suas receitas e quitação de suas obrigações em tempo razoável. Com isso, é possível identificar um ponto semelhante entre todas essas finalidades: obtenção de uma verdadeira sustentabilidade no futebol. ${ }^{18} \mathrm{E}$ com o intento de garantir a aplicabilidade de tais objetivos, em junho de 2012, o Comitê Executivo da UEFA aprovou a criação bicameral do Club Financial Control Body (CFCB).

Michel Platini, presidente da UEFA, e também presidente na ocasião, em entrevista 19 concedida, no ano de constituição (2009) do fair play financeiro, ao jornal americano The New York Times, afirmou que somente foi eleito como presidente porque prometeu que criaria para o futebol um

18 UEFA. UEFA Club Licensing and Financial Fair Play Regulations: Edition 2015. Disponível

<http://www.uefa.org/MultimediaFiles/Download/Tech/uefaorg/General/02/26/28/41/22 62841_DOWNLOAD.pdf> Acesso em: 22 de ago. 2015. p.2

19 HUGHES, Rob. Former Star on the Soccer Field Tries to Level It. The saturday profile. The New York Times, 31 de out. 2009. Disponível em: <http://www.nytimes.com/2009/10/31/world/europe/31platini.html?_r=1>. Acesso em: 22 de ago. 2015 
SILVA, Lucas do Monte. SILVA, Leonardo do Monte. Futebol-empresa: análise da lei de responsabilidade fiscal do futebol brasileiro. Revista Eletrônica Direito e Política, Programa de PósGraduação Stricto Sensu em Ciência Jurídica da UNIVALI, Itajaí, v.11, n.2, 2o quadrimestre de 2016. Disponível em: www.univali.br/direitoepolitica - ISSN 1980-7791.

fair play financeiro ("I was elected by the national associations because I promised to make financial fair play in soccer").

À época, se cogitou a efetividade na aplicação de tais medidas para os clubes brasileiros, tendo em vista a enorme disparidade existente entre as equipes brasileiras. Não havia, e até hoje não há, um repasse de forma igualitária dos rendimentos adquiridos com os clubes, como por exemplo, na distribuição dos direitos de imagem.

Mesmo após todo esse período decorrido da criação desse sistema, somente no mês de março ${ }^{20}$ de 2015, a Confederação Brasileira de Futebol (CBF) incluiu nos regulamentos específicos dos Campeonatos Brasileiros de 2015, tanto para Série A, B e C uma espécie do fair play financeiro: o fair play trabalhista, que foram aprovados por unanimidade pelos Conselhos Técnicos. A inovação reside na hipótese de punições aos clubes que atrasarem os salários de seus jogadores.

Segundo 0 art. 18 desse regulamento 21 , o clube que, por período igual ou superior a 30 dias, estiver em atraso com o pagamento de remuneração a atleta profissional registrado, ficará sujeito à perda de 3 pontos por partida a ser disputada, depois de reconhecida a mora e o inadimplemento por decisão do Superior Tribunal de Justiça Desportiva (STJD). Caso comprovado ser o clube devedor, caberá ao STJD conceder um prazo mínimo de 15 dias para que o clube inadimplente cumpra com suas obrigações financeiras em atraso, de modo a evitar a aplicação da sanção de perda de pontos por partida.

${ }^{20}$ CONFEDERAÇÃO BRASILEIRA DE FUTEBOL. Conselho Técnico da Série A aprova Fair Play Trabalhista por unanimidade. Disponível em: <http://www.cbf.com.br/noticias/campeonato-brasileiro-serie-a/conselho-tecnico-daserie-a-aprova-fair-play-trabalhista-por-unanimidade\#.VdjKhnjfCp0> Acesso em: 22 de ago. 2015

21 CONFEDERAÇÃO BRASILEIRA DE FUTEBOL. Regulamento Específico da Competição Campeonato Brasileiro da Série A 2015. Disponível em: <http://cdn.cbf.com.br/content/201503/20150309185448_0.pdf> Acesso em: 22 de ago. 2015. p. 12 
SILVA, Lucas do Monte. SILVA, Leonardo do Monte. Futebol-empresa: análise da lei de responsabilidade fiscal do futebol brasileiro. Revista Eletrônica Direito e Política, Programa de PósGraduação Stricto Sensu em Ciência Jurídica da UNIVALI, Itajaí, v.11, n.2, 2o quadrimestre de 2016. Disponível em: www.univali.br/direitoepolitica - ISSN 1980-7791.

Com a conversão da Medida Provisória no 671 na Lei de Responsabilidade Fiscal do Esporte (Lei no 13.155/15), o fair play financeiro, conforme visto alhures, passa a ser previsto de forma expressa no art. $2^{\circ}$ e no art. $4^{\circ}$, IX:

"Art. $2^{\circ}$ - Fica criado o Programa de Modernização da Gestão e de Responsabilidade Fiscal do Futebol Brasileiro - PROFUT, com o objetivo de promover a gestão transparente e democrática e o equilíbrio financeiro das entidades desportivas profissionais de futebol.

(...)

Art. $4^{\circ}$ - Para que as entidades desportivas profissionais de futebol mantenham-se no Profut, serão exigidas as seguintes condições:

(...)

IX - demonstração de que os custos com folha de pagamento e direitos de imagem de atletas profissionais de futebol não superam $\mathbf{8 0 \%}$ (oitenta por cento) da receita bruta anual das atividades do futebol profissional.

$(\ldots)^{\prime \prime}$ (grifos nosso)

O parágrafo $4^{\circ}$ do art. $4^{\circ}$ prevê ainda uma forma de mitigação desse fair play ao dispor que:

"§ $4^{\circ}$ - As entidades desportivas profissionais com faturamento anual inferior a uma vez e meia o teto do faturamento da empresa de pequeno porte de que trata o inciso II do art. $3^{\circ}$ da Lei Complementar no 123, de 14 de dezembro de 2006, ficam dispensadas do cumprimento do disposto nos íncisos $\mathrm{V}$ e IX do caput deste artigo e, quanto ao disposto no inciso VI do caput deste artigo, ficam autorizadas a contratar contador para o exercício da função de auditor independente." (grifo nosso)

A implementação do FFP no futebol brasileiro ainda é rudimentar. Somente em 2015, ou seja, 6 anos após a UEFA implementar esse sistema na Europa é que o Brasil passou a se utilizar dessa ideologia.

À primeira vista, o FFP da UEFA parece ser uma medida válida para 
SILVA, Lucas do Monte. SILVA, Leonardo do Monte. Futebol-empresa: análise da lei de responsabilidade fiscal do futebol brasileiro. Revista Eletrônica Direito e Política, Programa de PósGraduação Stricto Sensu em Ciência Jurídica da UNIVALI, Itajaí, v.11, n.2, 2o quadrimestre de 2016. Disponível em: www.univali.br/direitoepolitica - ISSN 1980-7791.

corrigir a crise no futebol mundial, mas certamente, não é a solução definitiva para os problemas existentes.

Em 2012 22, a UEFA impôs as suas primeiras sanções financeiras utilizando-se do fair play financeiro através da interrupção temporária de dinheiro de premiações de 23 clubes por não cumprir com as regras estabelecidas.

Outros clubes, também, foram severamente multados, como o Paris Saint-Germain (França) e Manchester City (Inglaterra), para ambos, as multas chegam a 60 milhões de euros.

Por outro lado, não será através de legislações sem efetividade que o fair play financeiro será concretizado. É cediço de que o fair play financeiro ajudou e ainda auxilia a conter o excesso de gastos dos clubes desde que foi introduzido. No entanto, essa limitação de gastos impede, por consequência, o crescimento de clubes menores que não são autorizados a gastar mais, propiciando que os grandes clubes dominem as competições europeias e, futuramente, as brasileiras. Essa igualdade de gastos poderá não ajudar na estabilidade dos clubes a longo prazo, isto quer dizer que os grandes clubes continuarão como grandes.

\section{GOVERNANÇA DESPORTIVA: A DESCONSIDERAÇÃo DA PERSONALIDADE JURÍDICA NO CASO DA GESTÃO TEMERÁRIA}

Outro aspecto importante da LRFE é o incentivo à governança desportiva ${ }^{23}$, por meio da responsabilização dos dirigentes pela gestão temerária. Em seu art. 24, da lei 13.155, dispõe que independentemente

\footnotetext{
22 BBC. Football: Uefa hands out first financial fair play penalties. Disponível em: < http://www.bbc.com/sport/0/football/19557934> Acesso em: 22 de ago. 2015

${ }^{23}$ A governança desportiva que tem como característica a "impessoalidade burocrática, da busca da consecução dos objetivos pré-definidos da forma mais econômica e eficiente possível", que se "contrapõe ao tradicional caráter amador e de abnegação na gestão do futebol, em que a paixão pela camisa do clube ou raiva do time adversário pode obscurecer as decisões tomadas" (LEONCINI, Marvio P.; SILVA, Marcia T. Entendendo o futebol como um negócio: um estudo exploratório. Revista Gestão e Produção. Vol. 12 , no. 1 , p. 11 a 23,2005 , p. $12-13$ )
} 
SILVA, Lucas do Monte. SILVA, Leonardo do Monte. Futebol-empresa: análise da lei de responsabilidade fiscal do futebol brasileiro. Revista Eletrônica Direito e Política, Programa de PósGraduação Stricto Sensu em Ciência Jurídica da UNIVALI, Itajaí, v.11, n.2, 2o quadrimestre de 2016. Disponível em: www.univali.br/direitoepolitica - ISSN 1980-7791.

da forma jurídica adotada, os dirigentes das entidades desportivas profissionais de futebol têm seus bens particulares sujeitos ao disposto no art. 50 do Código Civil, no qual constitui-se a possibilidade de desconsideração da personalidade jurídica nos casos de desvio de finalidade e confusão patrimonial (Teoria Maior).

A acepção de "dirigente", para a LRFE, é todo aquele que exerça, de fato ou de direito, poder de decisão na gestão da entidade, inclusive seus administradores. Com isso, a lei dispõe de um conceito amplo, uma vez que não são poucas as pessoas em entidades desportivas que possuem grande quantidade de pessoas que possuem poder de decisão na gestão, sobretudo considerando a falta de profissionalismo de diversos clubes que em vez de contratar uma equipe preparada para sua gestão, prefere ser coordenada por torcedores e dirigentes despreparados.

Sobreleva destacar que a responsabilidade ${ }^{24}$ desses dirigentes é solidária e ilimitada pelos atos ilícitos praticados e pelos atos de gestão irregular ou temerária ou contrários ao previsto no contrato social ou estatuto. Solidária e ilimitada são duas características fundamentais para a eficácia dessa lei, assegurando que haja uma efetiva aplicação, de modo que, por meio de lacunas jurídicas, os dirigentes não consigam esquivar-se da responsabilização cível.

Mas, no entanto, o que poderia ser considerados atos de gestão irregular ou temerária? Segundo o art. 25, da lei 13.155, são os atos praticados pelo dirigente aqueles que revelem desvio de finalidade na direção da entidade ou que gerem risco excessivo e irresponsável para seu patrimônio, e exemplifica: I - aplicar créditos ou bens sociais em proveito

${ }^{24}$ Ressalta-se que, segundo o art. 26 da LRFE, os dirigentes que praticarem atos de gestão irregular ou temerária poderão ser responsabilizados por meio de mecanismos de controle social internos da entidade, sem prejuízo da adoção das providências necessárias à apuração das eventuais responsabilidades civil e penal. Nota-se, assim, que trata-se de faculdade (a lei usa o termo "poderão" de cada entidade para reger a responsabilização quanto a ato social, do ponto de interno, sem afetar a responsabilidade civil e penal. 
SILVA, Lucas do Monte. SILVA, Leonardo do Monte. Futebol-empresa: análise da lei de responsabilidade fiscal do futebol brasileiro. Revista Eletrônica Direito e Política, Programa de PósGraduação Stricto Sensu em Ciência Jurídica da UNIVALI, Itajaí, v.11, n.2, 2o quadrimestre de 2016. Disponível em: www.univali.br/direitoepolitica - ISSN 1980-7791.

próprio ou de terceiros; II - obter, para si ou para outrem, vantagem a que não faz jus e de que resulte ou possa resultar prejuízo para a entidade desportiva profissional; III - celebrar contrato com empresa da qual o dirigente, seu cônjuge ou companheiro, ou parentes, em linha reta, colateral ou por afinidade, até o terceiro grau, sejam sócios ou administradores, exceto no caso de contratos de patrocínio ou doação em benefício da entidade desportiva; IV - receber qualquer pagamento, doação ou outra forma de repasse de recursos oriundos de terceiros que, no prazo de até um ano, antes ou depois do repasse, tenham celebrado contrato com a entidade desportiva profissional; dentre outras situações dispostas no referido artigo.

Além disso, também será considerado ato de gestão irregular ou temerária o recebimento de qualquer pagamento, doação ou outra forma de repasse de recursos por: I - cônjuge ou companheiro do dirigente; II parentes do dirigente, em linha reta, colateral ou por afinidade, até o terceiro grau; e III - empresa ou sociedade civil da qual o dirigente, seu cônjuge ou companheiro ou parentes, em linha reta, colateral ou por afinidade, até o terceiro grau, sejam sócios ou administradores.

Primeiramente, cabe ressaltar que se trata de rol exemplificativo, uma vez que além de utilizar termos indeterminados "desvio de finalidade" e "risco excessivo e irresponsável", os quais já possuem tratamento semelhante no art. 50 do Código Civil, que dependem da interpretação do magistrado com vistas nas particularidades do caso concreto, a lei usa a expressão "tais como" para apresentar os exemplos acima verificados.

A normativa apresentada também busca coibir as "dinastias" que diversos clubes de futebol possuem, passando a gestão dos clubes de maneira hereditária, como se fossem bens de suas famílias e, não, um empresa 
SILVA, Lucas do Monte. SILVA, Leonardo do Monte. Futebol-empresa: análise da lei de responsabilidade fiscal do futebol brasileiro. Revista Eletrônica Direito e Política, Programa de PósGraduação Stricto Sensu em Ciência Jurídica da UNIVALI, Itajaí, v.11, n.2, 2o quadrimestre de 2016. Disponível em: www.univali.br/direitoepolitica - ISSN 1980-7791.

com dirigentes e uma gestão adequada ${ }^{25}$. Com efeito, até proibindo qualquer tipo de pagamento aos parentes de terceiro grau e suas respectivas empresas, de modo a evitar o uso de parentes como disfarces para o desvio de finalidade.

Sobrelevar notar, no entanto, as causas excludentes de responsabilidade, quais sejam: I - quando o agente não tenha agido com culpa grave ou dolo; ou II - comprove que agiu de boa-fé e que as medidas realizadas visavam a evitar prejuízo maior à entidade. Destaca-se o uso da expressao "culpa grave" e não apenas "culpa", trazendo mais um conceito indeterminado para ser densificado pelo julgador no caso concreto.

Além disso, também não são considerados atos de gestão irregular ou temerária o aumento de endividamento decorrente de despesas relativas ao planejamento e à execução de obras de infraestrutura, tais como estádios e centros de treinamento, bem como a aquisição de terceiros dos direitos que envolvam a propriedade plena de estádios e centros de treinamento: I - desde que haja previsão e comprovação de elevação de receitas capazes de arcar com o custo do investimento; e II - desde que estruturados na forma de financiamento-projeto, por meio de sociedade de propósito específico, constituindo um investimento de capital economicamente separável das contas da entidade.

Quanto ao ressarcimento, compete à entidade desportiva profissional, mediante prévia deliberação da assembleia geral, adotar medida judicial cabível contra os dirigentes para ressarcimento dos prejuízos causados ao seu patrimônio. Em tais casos, os dirigentes em tela ficarão impedidos e deverão ser substituídos na mesma assembleia.

\section{CONSIDERAÇÕES FINAIS}

25 ALVITO, M. A parte que te cabe nesse latifúndio: o futebol brasileiro e a globalização. Análise Social, Lisboa, v. 41, n.179, p.451-474, 2006. 
SILVA, Lucas do Monte. SILVA, Leonardo do Monte. Futebol-empresa: análise da lei de responsabilidade fiscal do futebol brasileiro. Revista Eletrônica Direito e Política, Programa de PósGraduação Stricto Sensu em Ciência Jurídica da UNIVALI, Itajaí, v.11, n.2, 2o quadrimestre de 2016. Disponível em: www.univali.br/direitoepolitica - ISSN 1980-7791.

Por todo o exposto, conclui-se que a Lei de Responsabilidade Fiscal do Esporte apresenta os moldes necessários que o futebol brasileiro tenha como pauta o fair-play financeiro. A União utiliza-se das vultosas dívidas das entidades desportivas para incentivar a modernização do futebol. Possibilita o parcelamento das dívidas que, no total, somam mais de $\mathrm{R} \$ 2$ bilhões, mais, como contraprestação, exige que tais entidades respeitem determinadas condições ao adentrar no Profut, as quais são fundamentais para o fair-play financeiro e a sustentabilidade dos clubes-empresas.

No que se refere ao Profut, nota-se que apesar do alto número de condições expostas, estes são balizas fundamentais para que as entidades, mesmo que de meio coercitivo, as respeitem, sob pena de perder a possibilidade de parcelamento.

Já que no que tange a responsabilização dos dirigentes por atos de gestão temerária, nota-se que a lei em comento adota a teoria maior, sendo passível de responsabilização solidária e ilimita o(s) dirigente(s) que atuarem com desvio de finalidade ou realizem atividades com risco excessivo e irresponsável.

Trata-se de modos adotados pelo legislador que, a priori, possuem dois benefícios: a) com o parcelamento das dívidas, pelo menos há um pagamento, mesmo que em pequenas parcelas divididas em até 20 anos, das dívidas em vez de apenas não executá-las, como ocorre em determinados casos de possível execução fiscal; b) e, aliado a esse parcelamento, o Estado, por meio da imposição de diversas condições, assegura a modernização do gestão do futebol, por meio de ideias como o fair-play financeiro, a partipação dos atletas em certas decisões das entidades e a publicação das contas financeiras dos clubes.

\section{REFERÊNCIAS DAS FONTES CITADAS}


SILVA, Lucas do Monte. SILVA, Leonardo do Monte. Futebol-empresa: análise da lei de responsabilidade fiscal do futebol brasileiro. Revista Eletrônica Direito e Política, Programa de PósGraduação Stricto Sensu em Ciência Jurídica da UNIVALI, Itajaí, v.11, n.2, 2o quadrimestre de 2016. Disponível em: www.univali.br/direitoepolitica - ISSN 1980-7791.

ALVES, José Antônio Barros; PIERANTI, Octavio Penna. O estado e a formulação de uma política nacional de esporte no Brasil. RAE electron., São Paulo, v. 6, n. 1, June 2007. Disponível em: $<$ http://www.scielo.br/scielo.php?script=sci_arttext\&pid=S1676$56482007000100002 \&$ lng $=$ en\&nrm $=$ iso $>$.

ALVITO, M. A parte que te cabe nesse latifúndio": o futebol brasileiro e a globalização. Análise Social, Lisboa, v. 41, n.179, p.451-474, 2006

CONCEIÇÃO, Lucas Gonçalves; COSTA, Eder Dion de Paula. A emancipação social por meio da economia solidária: o caso da Conforja como uma concreta possibilidade. Revista Direito e Liberdade, Natal, v. 17, n. 3, p. 139-157, set./dez. 2015. Quadrimestral.

CONFEDERAÇÃO BRASILEIRA DE FUTEBOL. Conselho Técnico da Série A aprova Fair Play Trabalhista por unanimidade. Disponível em: <http://www.cbf.com.br/noticias/campeonato-brasileiro-serie-a/conselhotecnico-da-serie-a-aprova-fair-play-trabalhista-porunanimidade\#.VdjKhnjfCp0> Acesso em: 22 de ago. 2015

CONFEDERAÇÃO BRASILEIRA DE FUTEBOL. Regulamento Específico da Competição Campeonato Brasileiro da Série A 2015. Disponível em: <http://cdn.cbf.com.br/content/201503/20150309185448_0.pdf> Acesso em: 22 de ago. 2015.

UEFA. UEFA Club Licensing and Financial Fair Play Regulations: Edition 2015. Disponível em: <http://www.uefa.org/MultimediaFiles/Download/Tech/uefaorg/General/0 2/26/28/41/2262841_DOWNLOAD.pdf> Acesso em: 22 de ago. 2015.

FERKINS, Lesley; SHILBURY, David; MCDONALD, Gael. The role of the board in building strategic capability: Towards an integrated model of sport governance research. Sport Management Review 8.3 (2005): 195-225.

HUGHES, Rob. Former Star on the Soccer Field Tries to Level It. The saturday profile. The New York Times, 31 de out. 2009. Disponível em: <http://www.nytimes.com/2009/10/31/world/europe/31platini.html?_r=1 >. Acesso em: 22 de ago. 2015

GLOBOESPORTE.COM. Conselho Fiscal reprova contas do Vasco pelo quarto ano consecutive. Disponível em: <http://globoesporte.globo.com/futebol/times/vasco/noticia/2013/12/con selho-fiscal-reprova-contas-do-vasco-pelo-quarto-ano-consecutivo.html>. Acesso em 20 set. 2015. 
SILVA, Lucas do Monte. SILVA, Leonardo do Monte. Futebol-empresa: análise da lei de responsabilidade fiscal do futebol brasileiro. Revista Eletrônica Direito e Política, Programa de PósGraduação Stricto Sensu em Ciência Jurídica da UNIVALI, Itajaí, v.11, n.2, 2o quadrimestre de 2016. Disponível em: www.univali.br/direitoepolitica - ISSN 1980-7791.

LEONCINI, Marvio P.; SILVA, Marcia T. Entendendo o futebol como um negócio: um estudo exploratório. Revista Gestão e Produção. Vol. 12, no. 1 , p. 11 a $23,2005$.

PERRUCI, Felipe Falcone. Clube-empresa: o modelo brasileiro para transformação dos clubes de futebol em sociedades empresárias. Dissertação (Mestrado em Direito) - Curso de Mestrado da Faculdade de Direito Milton Campos, Faculdade de Direito Milton Campos, Nova Lima, 2006.

SANTOS, L.M.V. A Evolução da Gestão no Futebol Brasileiro. Dissertação de Mestrado. Fundação Getúlio Vargas/ Escola de Administração de Empresas de São Paulo: São Paulo, 2002 .

SOARES, Mario Luiz. A miopia do marketing esportivo dos clubes de futebol no Brasil: proposta de um modelo de gestão de marketing esportivo para os clubes brasileiros. 2007. Tese (Doutorado em Administração) - Faculdade de Economia, Administração e Contabilidade, Universidade de São Paulo, São Paulo, 2007.

SOUZA, Gabriel Menandro Evangelista de. Adoção do regime de empresa e o futebol profissional. 2005. 82 f. Trabalho de Conclusão de Curso. (Graduação em Direito) - Centro Universitário de Brasília.

VEJA. Dívida Ativa da União - Clubes de futebol. Disponível em: <http://veja.abril.com.br/complemento/esporte/pdf/dividas-timesfutebol.pdf>. Acesso em: 21 set. 2015

Submetido em: Janeiro de 2016.

Aprovado em: Junho de 2016. 